\title{
Resection and Reconstruction of Suprahepatic IVC and Right Atrium for Invasive Intrahepatic Cholangiocarcinoma
}

Brian B. Whang ${ }^{1}$, Manoj K. Singh ${ }^{2}$, Roshan Patel ${ }^{3}$, Marcelo E. Facciuto ${ }^{4}$, Arlen G. Fleisher ${ }^{5}$

1. Division of Thoracic Surgery, Brigham \& Women’s Hospital, Harvard Medical School 2. Medanta Liver Institute, Medanta The Medicity 3. Department of Pathology, Westchester Medical Center, New York Medical College 4. Recanati Miller Transplantation Institute, Mount Sinai School of Medicine 5. New York Medical College

$\square$ Corresponding author: Manoj K. Singh, msingh78@gmail.com

Disclosures can be found in Additional Information at the end of the article

\section{Abstract}

Surgical resection of intrahepatic cholangiocarcinoma with major vascular and atrial invasion is described in this case report using cardiopulmonary bypass followed by complex vascular reconstruction.

Categories: Cardiac/Thoracic/Vascular Surgery, Pathology, General Surgery

Keywords: cholangiocarcinoma, atrium, hepatic tumor, cardiopulmonary bypass, surgery

\section{Introduction}

Cholangiocarcinoma is a primary hepatic tumor that arises from the biliary ductal epithelium. Early symptoms are uncommon unless it occurs at or distal to the hepatic duct bifurcation, so many patients present with large, often unresectable tumors. Here we report the case of an intrahepatic cholangiocarcinoma invading the suprahepatic inferior vena cava (IVC) and right atrium, along with our surgical approach and technique for reconstruction.

\section{Case Presentation}

A 47 year-old woman was incidentally found to have a liver mass during workup for an asymptomatic umbilical hernia. Computed tomography of the abdomen and pelvis demonstrated a non-enhancing $3 \mathrm{~cm}$ mass in the left aspect of the caudate lobe of the liver. This mass was adjacent to the inferior vena cava and appeared to invade the left hepatic vein and extend superiorly to the right atrium.

Received 01/18/2013

Review began 01/19/2013

Published 01/29/2013

\section{๑) Copyright 2013}

Whang et al. This is an open access article distributed under the terms of the Creative Commons Attribution License CC-BY 3.0., which permits unrestricted use, distribution, and reproduction in any medium, provided the original author and source are credited.
The patient was referred for surgical resection. The operation was performed with a team of hepatobiliary and cardiothoracic surgeons. First, abdominal exploration was done through a bilateral subcostal incision with midline extension. Upon palpation, the tumor invaded the suprahepatic IVC, the surrounding diaphragm, and extended into the right atrium. A left hepatectomy, including caudate lobe resection, starting with parenchymal transection was performed, leaving only the left and middle hepatic veins attached to the IVC. Next, a median sternotomy was performed, the cava were snared, the liver vascular inflow was controlled with a vascular clamp. The patient was placed on cardiopulmonary bypass with the inferior vena cava cannula inserted distal to the hepatic veins, the superior cava cannulated through the right atrial appendage, and the arterial cannula in the ascending aorta. The cava was then opened 1 $\mathrm{cm}$ caudal to the entrance of the left hepatic vein. The tumor was palpated superiorly past the 


\section{Cureus}

atriocaval junction. The inferior portion of the right atrium was resected $2 \mathrm{~mm}$ below the coronary sinus. The entire en bloc specimen was then removed from the operative field, which included the left lobe and caudate lobe of the liver, IVC, diaphragm, and right atrium (Figure 1).

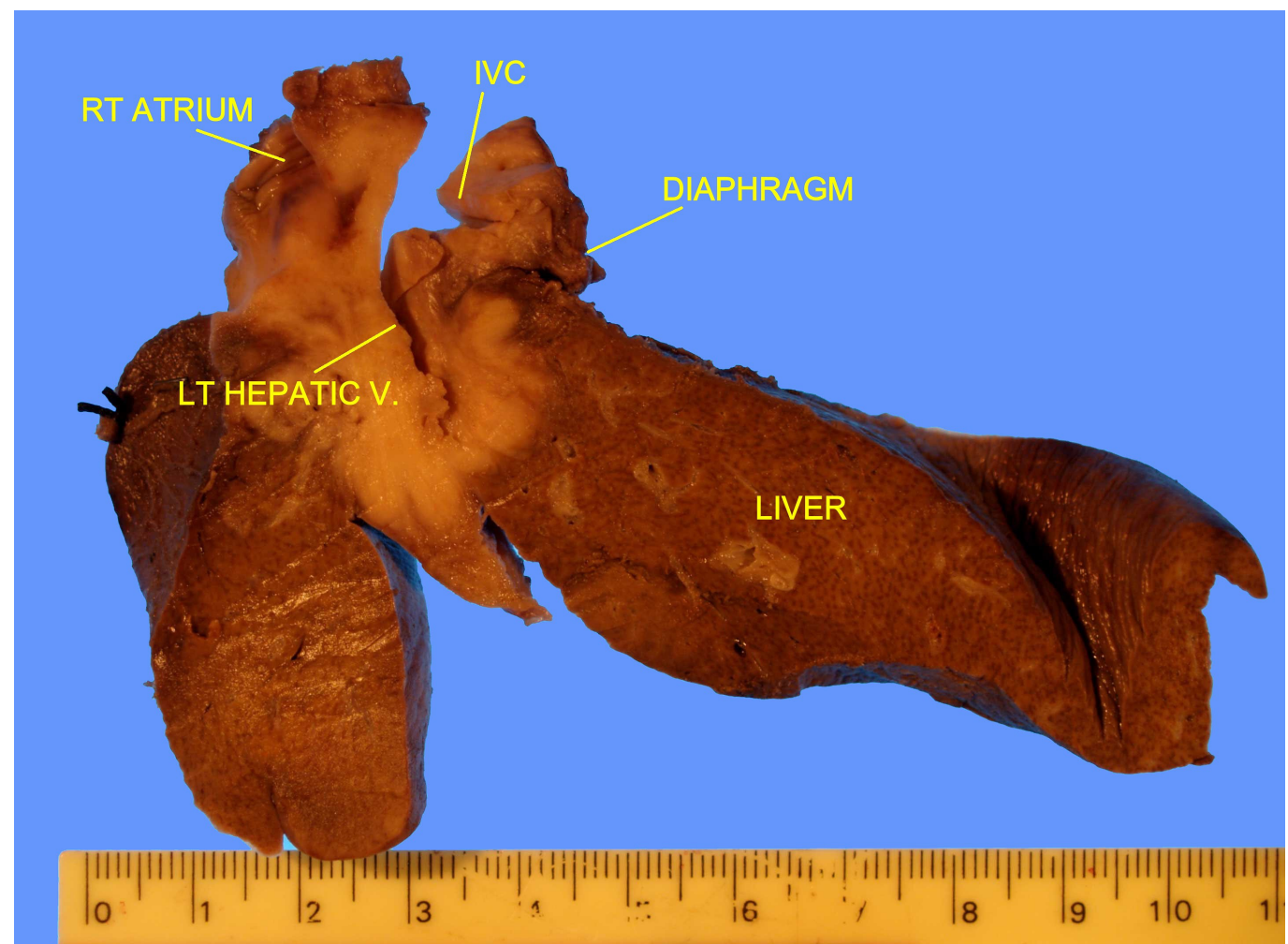

FIGURE 1: Pathological specimen showing extent of tumor spread.

The atriocaval junction was then reconstructed using $34 \mathrm{~mm}$ Hemashield tube graft (Boston Scientific, Natick, MA) (Figure 2). 


\section{Cureus}

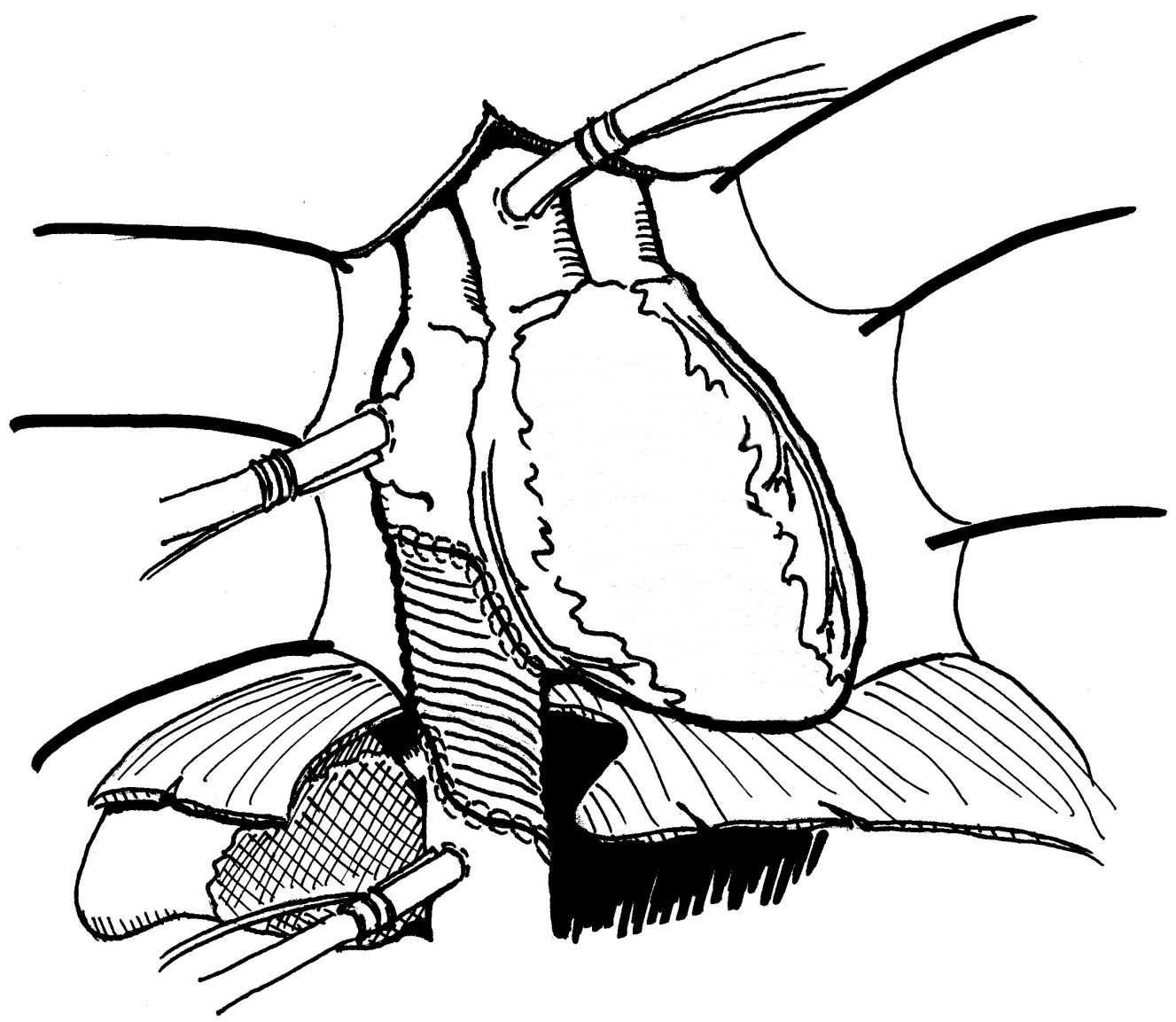

FIGURE 2: Reconstructed atriocaval junction with $34 \mathrm{~mm}$ Hemashield graft. The right atrium was resected $2 \mathrm{~mm}$ below the coronary sinus.

The inferior part of the graft was tailored to the preserved back wall and distal inferior vena cava just above the cannula. When this was completed, the patient was easily weaned from bypass and decannulated. The diaphragm was then reconstructed using Gore-Tex mesh (Gore, Tempe, AZ).

The patient's postoperative course was uneventful. Ultrasound of the liver demonstrated graft patency, and the patient was placed on low molecular-weight heparin to prevent thrombosis of the graft. Final pathology revealed infiltrating, poorly differentiated cholangiocarcinoma invading the left hepatic vein and extended through liver capsule and diaphragm into the wall of the right atrium.

\section{Discussion}

Surgical resection is the gold standard for cholangiocarcinoma. While chemotherapy, external beam radiation, and a combination of the two have been studied, there has not been compelling evidence to support the use of these modalities outside of a trial setting [1]. Some specialized centers have taken an aggressive surgical approach to tumors that invade adjacent vascular structures, and extended hepatic resections with caval reconstruction have been successfully performed [1,2]. Five-year survival for intrahepatic cholangiocarcinoma ranges from $8 \%$ to $47 \%$, depending upon the ability to achieve negative (R0) margins [1]. Lang et al. have achieved a median survival of 46 months with a calculated one- and three-year survival 
rate of $94 \%$ and $82 \%$, respectively, for R0 resection [2]. However, the median survival drops to five months for R1 resection (microscopic tumor at margins), and the calculated one-year survival is $22 \%$. Stage greater than I, multifocality, lymph node involvement, and vascular invasion are poor prognostic factors [2].

Intracardiac extension of hepatic tumors presents an even greater challenge to resectability. There are some advanced cases that have presented with Budd-Chiari syndrome $[3,4]$. While there are scant reports in the literature describing the successful resection of hepatocellular carcinoma with extension to the heart, there is no such documentation for cholangiocarcinoma [4-7]. Removal of the tumor without disturbing its integrity precludes traditional methods of vascular control. Facciuto et al. and Azoulay et al. describe several techniques for the resection of tumors at the hepatocaval confluence, including total vascular exclusion with transdiaphragmatic intrapericardial control of the cava, veno-venous bypass, and in situ hypothermic perfusion of the liver [8,9]. However, the presence of tumor within a cardiac chamber requires the application of cardiopulmonary bypass (CPB) for resection. The success of this technique and its positive impact on survival have been demonstrated in the extirpation of hepatocellular and renal cell carcinoma [7,10-12]. Invasion of the heart and great vessels by thoracic malignancies have also been successfully treated with aggressive resection on cardiopulmonary bypass. Park et al. have shown that the use of CPB itself did not lead to major morbidity, and that curative resection can be safely achieved [13].

\section{Conclusions}

Hepatic tumors with extensive local invasion involving major vascular and cardiac chambers can be safely resected. The literature supports an aggressive surgical approach and the use of $\mathrm{CPB}$ if the tumor can be completely resected and requires complex vascular reconstruction. Our patient presented with an intrahepatic cholangiocarcinoma, a tumor whose mainstay of treatment is surgical resection. A team approach between specialized hepatobiliary and cardiothoracic surgeons enabled complete extirpation of the tumor.

\section{Additional Information \\ Disclosures}

Human subjects: All authors have confirmed that this study did not involve human participants or tissue. Conflicts of interest: In compliance with the ICMJE uniform disclosure form, all authors declare the following: Payment/services info: All authors have declared that no financial support was received from any organization for the submitted work. Financial relationships: All authors have declared that they have no financial relationships at present or within the previous three years with any organizations that might have an interest in the submitted work. Other relationships: All authors have declared that there are no other relationships or activities that could appear to have influenced the submitted work.

\section{References}

1. Khan SA, Thomas HC, Davidson BR, Taylor-Robinson SD: Cholangiocarcinoma. Lancet. 2005, 366:1303-14.

2. Lang H, Sotiropoulos GC, Fruhauf NR, et al: Extended hepatectomy for intrahepatic cholangiocellular carcinoma (ICC) Extended hepatectomy for intrahepatic cholangiocellular carcinoma (ICC): when is it worthwhile? Single center experience with 27 resections in 50 patients over a 5-year period. Ann Surg. 2005, 241:134-143.

3. Law JK, Davis J, Buckley A, Salh B: Intrahepatic cholangiocarcinoma presenting as the BuddChiari syndrome: a case report and literature review. Can J Gastroenterol. 2005, 19:723-728.

4. Saisse J, Hardwigsen J, Castellani P, Caus T, Le Treut YP: Budd-Chiari syndrome secondary to intracardiac extension of hepatocellular carcinoma. Two cases treated by radical resection. 
Hepatogastroenterology. Hepatogastroenterology. 2001, 48:836-839.

5. Miyazawa M, Torii T, Asano H, Yamada M, Toshimitsu Y, Shinozuka N, Koyama I: Does a surgery for hepatocellular carcinoma with tumor thrombus highly occupying in the right atrium have significance? A case report and review of the literature. Hepatogastroenterology. 2005, 52:216-216.

6. Uemura M, Sasaki Y, Yamada T, Eguchi H, Ohigashi H, Doki Y, Murata K, Miyashiro I, Ishikawa O, Takami H, Kobayashi T, Imaoka S: Surgery for hepatocellular carcinoma with tumor thrombus extending into the right atrium: report of a successful resection without the use of cardiopulmonary bypass. Hepatogastroenterology. 2004, 51:1259-1262.

7. Yogita S, Tashiro S, Harada M, Kitagawa T, Kato I: Hepatocellular carcinoma with extension into the right atrium: report of a successful liver resection by hepatic vascular exclusion using cardiopulmonary bypass. J Med Invest. 2000, 47:155-160.

8. Facciuto ME, Babu S, Marvin M, Choudhury M, Sheiner PA: Intrapericardial control of the inferior vena cava from the abdominal cavity. J Hepatobiliary Pancreat Surg. 2004, 11:286-289.

9. Azoulay D, Andreani P, Maggi U, et al: Combined liver resection and reconstruction of the supra-renal vena cava: the Paul Brousse experience. Ann Surg. 2006, 244:80-88.

10. Libertino JA, Zinman I, Watkins E Jr.: Long-term results of resection of renal cell cancer with extension into inferior vena cava. J Urol. 1987, 137:21-24.

11. Nesbitt JC, Soltero ER, Dinney CPN, et al: Management of renal cell carcinoma with inferior vena cava tumor thrombus. Ann Thorac Surg. 1997, 63:1592-1599.

12. Chiappini B, Savini C, Marinelli G, et al: Cavoatrial tumor thrombus: single-stage surgical approach with profound hypothermia and circulatory arrest, including a review of the literature. J Thorac Cardiovasc Surg. 2002, 124:684-688.

13. Park BJ, Bacchetta M, Bains MS, et al: Surgical management of thoracic malignancies invading the heart or great vessels. Ann Thorac Surg. 2004, 78:1024-1030. 